\title{
Sex Differences in Persistent Fatigue
}

\author{
Janneke van Mens-Verhulst, $\mathrm{PhD}$ \\ Jozien M. Bensing, PhD
}

\begin{abstract}
This study examines factors differentiating women and men who suffer from fatigue. It is based on diaries kept by Dutch citizens over a 21-day period between 1987-88.

The majority of those with persistent fatigue complaints (PFs) were male, middle-aged, lower-educated and unemployed, and they had more psychological and psycho-social problems than the incidental fatigue sufferers (IFs).

Factors differentiating the PFs from the IFs are not the same for both sexes. Moreover, on a number of socio-demographic variables PF men and women differed less from each other than IF men and women.

Future research should focus on the gender-specificity of the factors that lead to the development of persistent fatigue. [Article copies available for a fee from The Haworth Document Delivery Service: 1-800-342-9678. E-mail address: getinfo@haworth.com]
\end{abstract}

In recent years there has been a growing awareness of different forms of fatigue. Fatigue may vary considerably in duration and severity, it can be either a presenting symptom or primary complaint, and it has many correlates. Apart from biomedical factors such as anaemia, emphysema, asthma, arthritis or low blood pressure, non-biomedical categories of fa-

Janneke van Mens-Verhulst is Assistant Professor at the Department of Clinical and Health Psychology of Utrecht University and Visiting Professor at the University for Humanist Studies. Jozien M. Bensing is Professor at the Department of Clinical and Health Psychology of Utrecht University, and Director of the Netherlands Institute of Primary Health Care (NIVEL).

Address correspondence to: Prof. dr. J. van Mens-Verhulst, Department of Clinical and Health Psychology, Postbox 80140, 3508 TC Utrecht, The Netherlands (e-mail: J.vanMENS-VERHULST@FSW.RUU.NL).

Women \& Health, Vol. 26(3) 1997

(C) 1997 by The Haworth Press, Inc. All rights reserved. 
tigue-specific factors have been identified. Among these, psychological factors have been the most thoroughly investigated. In general, fatigue symptoms are correlated with depression, anxiety and emotional stress (Bensing \& Schreurs, 1995; Chen, 1986; Ridsdale, Evans, Jerrett, Mandalia, Osler \& Vora, 1993; Lewis \& Wessely, 1992). In addition, persistent fatigue symptoms are generally positively associated with possible mental health problems, as indicated, for example, on the General Health Questionnaire (GHQ) (Ridsdale et al. 1993, Pawlikowska, Chalder, Hirsch, Wallace, Wright, Wessely, 1994).

With respect to socio-demographic characteristics, employment and marital status correlate negatively with fatigue symptoms (Chen, 1986; Valdini, Steinhardt \& Jaffe, 1987), whereas findings on age, education and occupation are inconsistent (Bensing \& Schreurs, 1995; Chen, 1986; David, Pelosi, Mc Donald, Stephens, Ledger, Rathbone \& Mann, 1990; Lewis \& Wessely, 1992; Lawrie \& Pelosi, 1993, 1995; Morrison, 1980; Pawlikowska et al., 1994; Ridsdale et al., 1993; Sugarman and Berg, 1984; Tibblin, Bengtsson, Furunes \& Lapidus, 1990; Valdini, Steinhardt \& Jaffe, 1987; Valdini, Steinhardt, Valiventi \& Jaffe, 1988). These inconsistencies are likely to be due to methodological differences between the studies, particularly with respect to the selection of the population or to differences in measurement.

Systematic analyses of sex differences in fatigue complaints are rare and represent a relatively recent development, although many studies indicate that the majority of people complaining of fatigue are women, namely $66 \%$ or more (Lewis \& Wessely, 1992). Pawlikowska et al. (1994) found evidence for this gender difference even after controlling for psychological distress (GHQ-scores). Bensing and Schreurs (1995) reported that the incidence of fatigue complaints among men was strongly associated with physical handicaps and stressful life-events, whereas fatigue complaints among women were, to a certain extent, associated with psychological complaints and biological conditions (for example, menstruation and pregnancy). Moreover, fatigue complaints were unevenly distributed over social categories of men and women. Unemployed men and white-collar workers were more at risk than blue-collar workers, as were women charged with the care of children under the age of six, especially when care duties were combined with a job outside the home. Contrary to the common stereotype, full-time house-keeping did not result in fewer complaints of fatigue among women.

In general, there is a substantial variety in the techniques and timing of measurement. With respect to techniques, many studies concentrate on the differences between the people who report fatigue and those who do not, 
without differentiating among fatigue complaints as such. However, as the need for more discriminatory types of fatigue measurement has increased, questionnaires have been developed which are capable of charting symptomatology more precisely (David et al., 1990; Lawrie and Pelosi, 1993, 1995; Pawlikowska, 1994). For example, David et al. list the following items: tired easily; in need of rest; feeling sleepy; difficulty starting to do things; lack of concentration, energy and strength; and feeling weak.

With respect to timing, each stage in the referral system appears to produce its own selection bias. Most studies of persistent fatigue have been done in primary care or hospital settings. Thus, these tend to include the influence of illness behavior (e.g., the inclination to seek professional help) and referral patterns (Lewis \& Wessely, 1992). At present, to our knowledge, the only available community-based studies of fatigue are those of Bensing and Schreurs (1995), Chen (1986), Lawrie and Pelosi (1995) and Pawlikowska et al. (1994).

The aim of this study was to learn more about the differences within the fatigued population at a community level, systematically differentiated by sex. The null hypothesis was that there would be no difference between incidentally and persistently fatigued sufferers, whether men or women.

This article presents the social, psycho-social, psychological and morbidity differences which were found by testing the null hypothesis. It identifies several risk-factors in the development of persistent fatigue, and suggests that the processes involved are gender-specific. As such, it underlines the importance of distinguishing gender-specific social categories in future long term studies of fatigue. This may further the long term development of primary and secondary prevention strategies for specific target groups.

\section{METHODS}

The study was based on data collected in the Dutch National Survey of General Practitioners (DNSGP). This survey was conducted from 1987 1988 by the Netherlands Institute for Primary Care (NIVEL).

Participants in the DNSGP were selected from the registers of 161 general practitioners, organized in 101 practices. A random group of 13,066 participants was generated from a non-proportional stratified sample of 17,344 people. Stratification variables were region, level of urbanization, and distance to a hospital. As almost every resident Dutch national is registered with a GP, the sample could be regarded as representative of the Dutch population. The non-response ( $24 \%$ of the original sample) 
appeared to be due to people's incapacity or lack of motivation $(52.8 \%)$ and to their inaccessibility (41.8\%) (Foets \& Sixma, 1991).

The selected respondents were asked to take part in a home interview consisting of 189 questions. These questions included checklists for acute and chronic disorders, the GHQ30 (Goldberg, 1972) with 4/5 as cut-off point, for probable psychiatric morbidity and the Biographic Problem List (BIOPRO) as a measure of psycho-social well-being (Foets \& van der Velden, 1990; Vermand \& Bijl, 1995). Subsequently, 11,038 of the participants $(85 \%)$ agreed to keep a health diary for 21 days.

The diary was intended as a record of the day-to-day health status of the participants and, in the event of any complaints, their health-related behavior. If respondents recorded complaints, they were invited to describe the sensations and any related clusters of complaints in their own words. These were subsequently coded in 97 categories based on the International Classification for Primary Care-ICPC-categories (Lamberts \& Wood, 1987).

Alongside the space for registering complaints the diary contained three major sections: (a) the state of well-being, as indicated by scores on a 5-point Likert-scale covering health experience, activity level and mood; (b) the assessment of physical complaints, if any; (c) a list of 16 possible health-related actions (e.g., "I have adapted my diet, smoking or drinking pattern," "I have cut down activities," "I have applied a home remedy" or "I consulted my GP").

The answers in sections (b) and (c) were 'yes' or 'no' options. The diary totalled 21 pages, with 51 items to be filled in on one page each day. Only forms which had been correctly filled in were processed. Compliance and precision turned out to be reasonable (Kooiker, 1995). The resulting database numbered 8,524 cases $(77 \%)$.

For the purpose of this study we selected respondents aged 25 and older who had one or more complaints coded in the category encompassing fatigue, lack of energy, sleeplessness, nervousness, tension, stress, lack of concentration and amnesia. The final sample consisted of 394 men and 741 women ( $34.7 \%$ and $65.3 \%$ respectively). Thus $\mathrm{N}_{1}=1,135$. The persistence of fatigue was measured by aggregating the diary scores over 21 days.

As this study was intended to explore the differences between peoplewomen and men-with persistent and incidental fatigue complaints, comparing the 'tail end' of the frequency distribution with the rest seemed the most convincing approach. Since a group statistically should include at least 25 cases, a split was made between the group registering 20 or more fatigue days (2.2\%) and the group that registered 19 or less fatigue days 
$(97.8 \%)$. Consequently, incidental tiredness was largely excluded from the first group. The split resulted in a group of people $(\mathrm{N}=25)$ with almost persistent fatigue complaints (PFs) presumably extending over a period before and after the study. Fourteen of these PFs were men, eleven women. The others $(\mathrm{N}=1,110)$ were their incidentally fatigued counterparts (IFs) in this study; 380 men and 730 women.

We carried out separate contrast analyses between the groups of PFs and IFs as a whole, as well as within the different samples of men and women. Using this procedure it was possible to indicate the potential sex-specificity of factors underlying the differences in duration of fatigue complaints. We concentrated on the socio-demographic, psycho-social and psychological data. The results in the separate men and women samples were always checked but only differences that reached statistical significance are reported here.

Statistical analysis was performed using the SPSS program. Depending on the level of the variables (interval, ordinal or nominal), $t$-test, the Mann-Whitney test or Pearson's chisquare test were used in conjunction with a Bonferroni Correction procedure. (When a family of items was measured, the criteria for significance were elevated by dividing the required level by the total number of items involved. Hereby the probability of the total type I-error was kept within the limits of $0.05 \%$ ). If no normal distribution could be assumed, non-parametric statistics were applied.

The data presented here reflect the overall health behavior of both groups because it was impossible to separate out the assessment of and efforts to deal with fatigue complaints from those associated with other complaints.

\section{RESULTS}

\section{Socio-Demographic Characteristics}

Table 1 displays the skew frequency distribution of fatigue complaints (Skewness 2.8879, S.E. Skew .0726), with an increase in numbers of people with fatigue complaints persisting for 20 days or more. This increase coincides with a reversal in the absolute and relative representation of men and women at 21 days.

Table 2 presents the results of the analysis of socio-demographic differences. The group of PFs included significantly more men than women and was also notably older than the IFs. Members of this group also had a lower educational level (mostly primary). 
TABLE 1. Distribution of Fatigue Complaints in a 21-Day Registration

\begin{tabular}{rrrrrrr}
\hline $\begin{array}{c}\text { Frequency } \\
\text { of complaint }\end{array}$ & $\begin{array}{c}\text { Total } \\
\text { population }\end{array}$ & Perc & Women & Perc & Men & Perc \\
\hline 1 & 466 & 41.06 & 310 & 41.84 & 156 & 39.59 \\
2 & 265 & 23.35 & 165 & 22.27 & 100 & 25.38 \\
3 & 116 & 10.22 & 76 & 10.26 & 40 & 10.15 \\
4 & 75 & 6.61 & 55 & 7.42 & 20 & 5.08 \\
5 & 55 & 4.85 & 36 & 4.86 & 19 & 4.82 \\
6 & 37 & 3.26 & 22 & 2.97 & 15 & 3.81 \\
7 & 24 & 2.11 & 16 & 2.16 & 8 & 2.03 \\
8 & 11 & 0.97 & 10 & 1.35 & 1 & 0.25 \\
9 & 11 & 0.97 & 9 & 1.21 & 2 & 0.51 \\
10 & 6 & 0.53 & 3 & 0.40 & 3 & 0.76 \\
11 & 6 & 0.53 & 5 & 0.67 & 1 & 0.25 \\
12 & 5 & 0.44 & 2 & 0.27 & 3 & 0.76 \\
13 & 5 & 0.44 & 4 & 0.54 & 1 & 0.25 \\
14 & 5 & 0.44 & 4 & 0.54 & 1 & 0.25 \\
15 & 4 & 0.35 & 2 & 0.27 & 2 & 0.51 \\
16 & 3 & 0.26 & 2 & 0.27 & 1 & 0.25 \\
17 & 7 & 0.62 & 4 & 0.54 & 3 & 0.76 \\
18 & 1 & 0.09 & 1 & 0.13 & 0 & 0.00 \\
19 & 8 & 0.70 & 4 & 0.54 & 4 & 1.02 \\
20 & 8 & 0.70 & 5 & 0.67 & 3 & 0.76 \\
21 & 17 & 1.50 & 6 & 0.81 & 11 & 2.79 \\
\hline & 1135 & 100.00 & 741 & 100.00 & 394 & 100.00 \\
\hline
\end{tabular}

Their group differed significantly in the distribution of non-employment: the percentage of pensioners-regular and disabled-was higher and that of housewives and employed people lower. Children below the age of 6 did not make a difference for women or men.

Compared to the IF men, a significantly higher percentage of the persistently fatigued men lived alone, i.e., without a partner (35.7\% compared with $9.1 \%$ ). Among the women as a whole no significant differences in distribution of living arrangements were found. Within both groups of women, the PFs as well as the IFs, almost $25 \%$ lived alone ( 3 PF women did not answer this question). 
TABLE 2. Sociodemographic Differences Between Incidentally ( $N=1110$ ) and Persistently ( $N=25)$ Fatigued Women and Men

\begin{tabular}{|c|c|c|c|c|c|}
\hline & Chi-squar & $\mathrm{df}$ & $P$ & & \\
\hline $\begin{array}{l}\text { Sex } \\
\text { Living Alone }\end{array}$ & 5.11 & 1 & .023 & & \\
\hline \multirow{3}{*}{$\begin{array}{l}\text { total } \\
\text { women } \\
\text { men }\end{array}$} & 2.61 & 1 & .106 & & \\
\hline & 10.50 & 1 & .001 & & \\
\hline & .02 & 1 & .899 & & \\
\hline \multicolumn{6}{|l|}{ Marital Status } \\
\hline \multirow{2}{*}{$\begin{array}{l}\text { total } \\
\text { women }\end{array}$} & 5.4 & 1 & .463 & & \\
\hline & .24 & 1 & .620 & & \\
\hline \multirow{2}{*}{\multicolumn{6}{|c|}{$\begin{array}{c}\text { men } \\
\text { Non-employment }\end{array}$}} \\
\hline & & & & & \\
\hline total & 29.37 & 4 & .0005 & & \\
\hline \multicolumn{6}{|c|}{$\begin{array}{l}\text { women } \\
\text { men }\end{array}$} \\
\hline \\
\hline & 2.26 & 2 & .323 & & \\
\hline \multirow{4}{*}{$\begin{array}{l}\text { women } \\
\text { men }\end{array}$} & 1.12 & 2 & .568 & & \\
\hline & 1.22 & 2 & .541 & & \\
\hline & & & & IFs & PFs \\
\hline & t-value & $d \mathfrak{d}$ & $P$ & Mean & Mean \\
\hline \multicolumn{6}{|l|}{ Age } \\
\hline & -4.74 & 25.52 & .0005 & 43.37 & 54.76 \\
\hline \multirow{3}{*}{ men } & -2.94 & 14.18 & .014 & 43.69 & 55.54 \\
\hline & -3.76 & 10.38 & .002 & 42.75 & 54.14 \\
\hline & U-value & & & Mean Rank & Mean Rank \\
\hline \multicolumn{6}{|l|}{ Education } \\
\hline total & 7005.5 & & .0005 & 568.12 & 293.22 \\
\hline women & 1088.5 & & .012 & 368.88 & 210.27 \\
\hline men & 2247.0 & & .0005 & 200.11 & 85.25 \\
\hline
\end{tabular}

" not computable for the separate sexes

The PFs did not differ significantly from the IFs in their marital status or occupational classification.

\section{Well-Being}

Daily well-being. Differences in daily well-being were demonstrated on the 5-point Likert-scales. The PF group scored on average half a point 
higher (and thus felt 'worse') than the IFs. The mean score for health experiences was $2.8743(\mathrm{t}=-7.72,1133 \mathrm{df}, \mathrm{p}<.0005)$; for daily activities $2.8552(\mathrm{t}=-7.70,24.55 \mathrm{df}, \mathrm{p}<.0005)$; and for moods $2.5562(\mathrm{t}=-5.26$, $1133 \mathrm{df}, \mathrm{p}<.0005)$.

Psychological well-being. PFs scored higher on the GHQ (7.8, SE 1.2), suggesting that they may suffer more from psychological stress than the IFs (3.6, SE 0.2). In real terms, this meant that in the four weeks before they began keeping the diaries, the PFs experienced significantly more disorders in their psychological condition $(U=6338.5, p<.0005)$ than the IFs. Table 3 provides details.

At least five differences between PFs and IFs were revealed which were apparent in the female but not in the male samples throughout. These differences were also evident for the total population, but this could be due to the over-representation of women. The PF women presented an overall picture of distress. Their mean GHQ-score was 9.40, SE 2.02. The PF men differed from the IF only in that their ability to 'feel reasonably happy' was below average. Their mean GHQ-score was 6.62; SE 1.42.

Psycho-social problems. The PFs had a higher score (M 2.3, SE 0.2) on the biographic problem questionnaire (BIOPRO) than the IFs (M 1.4, SE 0.03 ). As such, they indicated significantly more problem areas in their social life. The details are in Table 4.

Separate inspection of the male and female groups revealed significant differences in types of differentiating problem areas, not in number. Amongst the men the problems with housing and life situation (neighborhood) were distinctive. Amongst the women, the 'sexual problems' and 'other problems' categories were distinctive. The men's groups were also distinguished by a higher incidence of problems with ageing and selfimage while the women's groups showed a trend only.

\section{Morbidity}

Apart from persistence of fatigue, PFs and IFs appeared not to differ in their physical condition. The level of chronic disorders, either 'severe' or 'moderate', was not significantly higher in the PF population. On the checklist of 27 chronic disorders the IF population scored $M=.194$ for the heavy chronic disorders and $\mathrm{M}=.291$ for the moderate chronic disorders, whereas the PFs scored $\mathrm{M}=.200$ in both cases (with respectively $\mathrm{U}=$ $13162.5 ; \mathrm{p}=.47$ and $U=13307.0 ; \mathrm{p}=.69)$. On the checklist of 45 acute disorders the IFs scored $\mathrm{M}=3.82$ (SE 0.1) and the PFs $\mathrm{M}=4.3(\mathrm{SE}=1)$ but again no significant differences were found $(U=13067.0 ; p=.60)$. 


\section{Dealing with the Fatigue Complaints}

The number of days on which the PF group took action to diminish their complaints was significantly higher $(M=.26)$ than that of the IFs $(\mathrm{M}=.09 ; \mathrm{p}<.0005)$. More specifically, they called upon professional help more frequently: consulting medical and other professionals as well as using prescribed medicines $(\mathrm{M}=.56$ compared to $\mathrm{M}=.14 ; \mathrm{U}=7932.0$; $\mathrm{p}<.0005$ ).

Differentiation by sex revealed a highly significant difference in consulting behavior for the samples of men $(p=.0002)$, but for the women nothing more than a trend $(p=.06)$.

\section{DISCUSSION}

The purpose of this study was to obtain insight into the differences between complaints of persistent and incidental fatigue as present within the community. Special attention was paid to the differences between PF and IF men on the one hand and PF and IF women on the other hand. Significant differences were found in socio-demographic characteristics, daily well-being and the number of psycho-social and psychological problems. No differences were found between the prevalence of acute and chronic diseases. Finally, some interesting differences between the sexes emerged.

\section{Methodological Considerations}

It has to be acknowledged that the intensity of the fatigue registered in the complaints was not recorded and that the period in which fatigue was studied was also short. Moreover the assumption that health complaints are veridical is a sign of naive realism about symptom reporting (Watson and Pennebaker, 1991). Nevertheless, it is unlikely that methodological weaknesses seriously affected our results.

In fact, our sample was more representative of the normal population than that of many other fatigue studies. Whereas most investigations have been performed in primary care or even secondary or tertiary referral settings (Pawlikowska et al., 1994), our study was community-based, representative and used repeated assessment.

We took great care to ensure the precision and rigor of our methodology throughout the study. Firstly, in the criterion used to identify people with persistent fatigue (i.e., they must not miss more than one day with a fatigue 
TABLE 3. Differences in Mental Well-Being Between Incidentally ( $N=$ $1110)$ and Persistently $(N=25)$ Fatigued Women and Men Measured by the GHQ-30.

\begin{tabular}{|c|c|c|c|c|c|}
\hline GHQ-ITEMS & $\begin{array}{l}\text { U-Value } \\
\text { Popula- } \\
\text { tion } \\
\mathrm{N}=1135\end{array}$ & $P$ & $\begin{array}{l}\text { U-Value } \\
\text { Women } \\
N=741\end{array}$ & $P$ & $\begin{array}{l}\text { U-Value } \\
\text { Men } \\
N=394\end{array}$ \\
\hline Restless and disturbed nights & 12641.5 & & 2953.5 & & 1614.0 \\
\hline $\begin{array}{l}\text { Felt on the whole you were doing } \\
\text { things well }\end{array}$ & 12933.5 & & 3391.5 & & 2625.0 \\
\hline Feel warmth and affection & 13084.0 & & 3545.0 & & 2626.5 \\
\hline Easy to get on with other people & 12599.0 & & 3257.5 & & 2622.0 \\
\hline Spent time changing & 11990.5 & & 3273.0 & & 2391.0 \\
\hline Playing a useful part & 12742.0 & & 3267.5 & & 2637.0 \\
\hline Constantly under strain & 11839.0 & & 2970.5 & & 2534.5 \\
\hline Couldn't overcome difficulties & 8288.5 & * & 2023.0 & & 1736 \\
\hline Finding life a struggle & 8541.5 & ** & 797.0 & $\star \star \star \star$ & 2529.0 \\
\hline Enjoy normal day activities & 9920.0 & & 2770.5 & & 1935.5 \\
\hline Taking things hard & 7648.0 & * & 1772.0 & & 1667.5 \\
\hline Everything on top of you & 7884.5 & ** & 1890.0 & & 1613.0 \\
\hline Life entirely hopeless & 7447.0 & $* * *$ & 1343.5 & 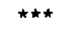 & 1867.0 \\
\hline Felt that life isn't worth living & 7659.5 & $* * *$ & 1237.5 & $* * \star *$ & 1995.5 \\
\hline Lost sleep over worry & 10452.0 & & 2941.5 & & 2019.0 \\
\hline Getting out of house & 11700.0 & & 2737.0 & & 2203.0 \\
\hline Contented with your lot & 9698.0 & & 2638.5 & & 1776.0 \\
\hline $\begin{array}{l}\text { Scared and panicky ... no } \\
\text { good reason }\end{array}$ & 9516.0 & & 2212.5 & & 1994.0 \\
\hline Able to face your problems & 12414.0 & & 3287.0 & & 2485.0 \\
\hline Losing confidence in yourself & 10976.0 & & 2770.5 & & 2259.0 \\
\hline Hopeful about your future & 10490.0 & & 2375.0 & & 2362.0 \\
\hline $\begin{array}{l}\text { Feeling nervous and strung up all } \\
\text { the time }\end{array}$ & 8300.0 & ** & 2000.0 & & 1722.5 \\
\hline $\begin{array}{l}\text { Couldn't do anything because } \\
\text { nerves were too bad }\end{array}$ & 9719.0 & & 2249.0 & & 2115.0 \\
\hline
\end{tabular}


TABLE 3 (continued)

\begin{tabular}{|c|c|c|c|c|c|}
\hline GHQ-ITEMS & $\begin{array}{l}\text { U-Value } P \\
\text { Popula- } \\
\text { tion } \\
\mathrm{N}=1135\end{array}$ & $\begin{array}{l}\text { U-Value } \\
\text { Women } \\
\mathrm{N}=741\end{array}$ & $P$ & $\begin{array}{l}\text { U-Value } \\
\text { Men } \\
N=394\end{array}$ & $P$ \\
\hline $\begin{array}{l}\text { Concentrate on whatever you are } \\
\text { doing }\end{array}$ & 11364.5 & 3025.0 & & 2264.0 & \\
\hline Managing as well as most people & 12843.5 & 3283.0 & & 2408.0 & \\
\hline Keep busy and occupied & 10503.5 & 2480.0 & * & 2270.5 & \\
\hline Capable of making decisions & 11723.0 & 3173.0 & & 2360.0 & \\
\hline Feeling unhappy and depressed & $8163.0 *$ & 1587.5 & $\star \star \star ~$ & 1828.5 & \\
\hline Thinking of yourself as worthless & 10061.0 & 3114.5 & & 1824.5 & \\
\hline Reasonably happy & $8395.5^{* * *}$ & 2431.0 & & 1568.0 & ** \\
\hline
\end{tabular}

complaint). Secondly, by applying the Bonferroni Correction Procedure on the criteria of significance.

The statistical power of our study was limited by the small number of respondents who registered 20 or more fatigue days. Thus, the error of the mean in this sample of 25 PFs might be relatively large, whereas it was small in the sample of $1,110 \mathrm{IFs}$. In addition, the power to demonstrate any differences was not high because the observed significance level was 0.05 . In adopting this level of significance we were risking the possibility of overlooking differences between IF and PF women and men, but ensured that the demonstrated differences were robust. The robustness of these differences has been confirmed through an additional contrast analysis with 19 complaints as breaking point which displayed the same patterns of difference.

In addition, the absence of differences is to be interpreted with caution because it does not necessarily indicate the presence of similarities.

Doubts may be raised about the validity of the identification of fatigue in this study in that this identification was based on a category of the ICPC that also includes malaises such as shortage of sleep and concentration. However, this combination of complaints is almost identical to the items that are used in the fatigue questionnaires. Consequently, this approach is not likely to undermine the validity of the outcome of our study.

Finally, it is known that using diaries for the assessment of the health 
TABLE 4. Differences in Psycho-Social Problems Between Incidentally $(N=$ $1110)$ and Persistently $(N=25)$ Fatigued Women and Men Measured by the Biographic Problem List (BIOPRO)

\begin{tabular}{|c|c|c|c|c|c|c|}
\hline & $\begin{array}{l}\text { Chi- } \\
\text { Square } \\
\text { Popula- } \\
\text { tion } \\
\mathrm{N}=1135\end{array}$ & $\begin{array}{l}P \\
5 \\
\end{array}$ & $\begin{array}{l}\text { Chi- } \\
\text { Square } \\
\text { Women } \\
\mathrm{N}=741\end{array}$ & $\mathbf{P}$ & $\begin{array}{l}\text { Chi } \\
\text { Square } \\
\text { Men } \\
N=394\end{array}$ & $P$ \\
\hline $\begin{array}{l}\text { PROBLEMS } \\
\text { 1. Financial }\end{array}$ & .55 & & 1.03 & & 4.42 & \\
\hline 2. Housing & 2.03 & & 1.12 & & 11.33 & * \\
\hline 3. Parents & .80 & & .45 & & .59 & \\
\hline 4. Education & .23 & & .12 & & .11 & \\
\hline 5. Job & 2.33 & & .92 & & 1.45 & \\
\hline 6. Ageing & 16.89 & 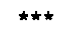 & 8.90 & & 10.05 & * \\
\hline 7. Partner/Marital & 1.25 & & 2.01 & & .65 & \\
\hline 8. Children & 3.58 & & .13 & & 4.70 & \\
\hline 9. Other Relationships & 4.11 & & 1.36 & & 2.62 & \\
\hline 10. Establishing Relationships & 0.01 & & .09 & & .20 & \\
\hline 11. Sexual & 9.97 & * & 11.61 & * & 1.67 & \\
\hline 12. Religious & 1.00 & & 1.96 & & .00 & \\
\hline 13. Self-Development & .03 & & 1.97 & & .99 & \\
\hline 14. Self-Image & 17.30 & $\star \star \star$ & 7.29 & & 13.76 & ** \\
\hline 15. Worry about the Future & 2.60 & & 1.76 & & 1.35 & \\
\hline $\begin{array}{l}\text { 16. Abuse of Alcohol, } \\
\text { Medicine, Illegal Drugs }\end{array}$ & .14 & & .57 & & .00 & \\
\hline 17. Loneliness & 1.58 & & 2.71 & & 20 & \\
\hline 18. Societal Change & 2.03 & & .85 & & 1.32 & \\
\hline 19. Neighborhood & 2.56 & & .99 & & 11.24 & * \\
\hline 20. Leisure Time & 3.22 & & 1.89 & & 1.52 & \\
\hline 21. Worry (in General) & 34.03 & 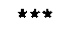 & 16.46 & $\star \star *$ & 17.42 & ** \\
\hline 22. Other Problems & 9.54 & * & 18.05 & 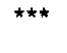 & .11 & \\
\hline
\end{tabular}

$*=p<.05 \quad * *=p<.01 \quad * * *=p<.001$ 
status of the entire population can lead to the under-representation of disadvantaged groups like the elderly or poorly educated (Kooiker, 1995). Therefore, one could expect a more adequate instrument to produce even stronger associations than we have found here.

\section{Socio-Demographic Characteristics}

The higher percentage of men in the group of PFs is remarkable in that it reverses the usual pattern showing higher rates of fatigue among women. However, it is in line with the findings of Ridsdale et al. (1993). At 6 months the 56 men in their study tended to have higher fatigue scores than women, although the difference was not significant. It is also consistent with David et al. (1990) who could not find significant sex differences on duration and frequency of fatigue; neither could Valdini et al. (1988) in their follow-up study. As such, one might assume that sex differences "disappear" with the persistence of the fatigue. However, in the only community study of 'people who always feel tired' measured over one month, the prevalence of women's fatigue was 29.8 , compared to a prevalence of men's fatigue of 18.9 (Cox, Blaxter, Buckle et al., 1987). This finding suggests that sex may be a mediating variable, or that sex is simply a correlate and that the impact of sex should be attributed to other determinants.

The finding that the PFs were older than the IFs is not consistent with the conclusion of the prospective study conducted by Ridsdale et al. (1993). However, their investigation concerned high fatigue scores over a period of six months and involved patients in a general practice. Our result also differs from the community study of Pawlikowski et al. (1994) which showed a very weak association for women only, but did not differentiate according to duration of fatigue. Lewis and Wessely (1992) hypothesized that inconsistencies on the age factor are due to methodological factors. It is also possible that there are simply no consistent associations.

Our observation of a lower educational level among the persistently fatigued agrees with the first study of Valdini et al. (1987) which was conducted on the sample from a University Family Health Center with not only an over-representation of women but also of patients in the 25-44 years age group ( $44 \%$ under 35 years of age). In that study, Valdini et al. concluded that patients with a college degree reported significantly less fatigue than those with a high school diploma or less. Reasons for these inverse relationships were unclear but may relate to life satisfaction and socio-economic status.

Our study contrasts with that of Bensing and Schreurs (1995). They found in their representative survey study among the Dutch population 
that there was a positive correlation between fatigue and the educational level. However, in their study fatigue was registered as the positive answer to the question 'have you felt fatigued in the last two weeks?' and not as a primary complaint. Nor are our results consistent with the second study of Valdini et al. (1988) conducted among a population with relatively few college graduates. In this follow-up study a sample of 115 fatigued and 139 non-fatigued adults in a county health center were twice given the Rand Index of Vitality (RIV). The second survey took place a year after the first and was conducted via telephone or mail. The information was completed by $64 \%$ of the patients who had originally reported themselves as fatigued and $53 \%$ of the patients who had originally reported to be non-fatigued. In this sample, $40.7 \%$ of respondents were aged between $18-30,34 \%$ between $31-60$ and $24 \%$ over 61 , and $71.7 \%$ of the total were women. In this study the educational status of the initially fatigued group showed no statistically significant difference when compared with those who were not fatigued, and it showed an inverse relationship when compared to the patients who continued to suffer from fatigue over the follow-up period (chi $=6.05, \mathrm{P}<.05$ ). The inconsistent results on educational level may be due to a combination of socio-demographic dissimilarities in the investigated populations on the one hand and the methods of fatigue measurement on the other hand. Additional study is necessary.

The differences in non-employment (among pensioners respectively housewives and employed people) are remarkable. They point to significant differences in the lifestyles of men and women in the Netherlands of 1987. For men, non-employment mainly meant having left the market of paid labour; thus unemployment. For women, non-employment referred first and foremost to their typical participation in the market of non-paid labour at home. In this study, the higher percentage of pensioners among the PFs than among the IFs is predominantly accounted for by men $(78.6 \%$ versus $15.3 \%$ ) whereas the smaller percentage of homekeepers is accounted for mainly by women $(27.3 \%$ versus $39 \%)$. However, the major shifts in employment status occurred between the samples of men. The profiles of the women's samples were not radically different. An explanation could be that men find non-employment difficult to cope with, whereas women may be more fatigued if they are working because they also have more domestic responsibilities.

Taking this into account, our results can be seen to follow those of Lawrie and Pelosi's $(1993,1995)$ survey of a random community sample. Having first controlled for physical illness, they could not establish a significant association of substantial fatigue with the non-employment of women. However, on the other hand, neither could they establish an 
association between fatigue and the retirement of both sexes. There would seem to be no direct equivalence between our category of 'persistent' fatigue with their 'substantial' fatigue, as their label refers to fatigue of at least six months' duration.

Marital status made no difference in our study. The number of single, divorced or widowed individuals in the groups of PF men and women was not significantly higher than among the IF. This seems to contrast with some other, cross-sectional, studies. For example, in their inquiries Morrison (1980) and Valdini et al. (1988) found that fatigue is more commonly diagnosed for single than for married patients. David et al. (1990) report a similar trend. However, all three investigations refer to primary healthcare patients. Moreover, in their follow-up study Valdini et al. (1987) concluded that marital status was not significantly associated with the development of fatigue or its improvement. This suggests that marital status does not influence the course of fatigue complaints as such, but it does influence the decision to consult a GP. This would be in line with Umberson's suggestion (1992) that married men benefit from the greater health awareness of their spouses who monitor their health and encourage them in positive health behavior.

It is also interesting to note that living arrangements are a significant differentiating factor between PF and IF men but not between PF and IF women. Several explanations can be given. Most obviously, the percentage of women living alone is already high in the group of IFs (25\%). An additional explanation is that fatigue is more likely to persist with men who live alone, because living alone imposes the double burden of labour outside and inside the home-a situation familiar to many women (Tibblin, Bengtsson, Furunes \& Lapidus, 1990). A third explanation has already been referred to above. It assumes that men, as opposed to women, deal with their fatigue complaints differently when they live alone than when they are living together with (female?) others. At any rate, our analysis demonstrates the importance of living alone as a factor in the course of persistent fatigue.

The age of children does not emerge as a differentiating factor between PFs and IFs either for men or for women. This finding does not, however, contradict the earlier results of Bensing and Schreurs (1995), rather it puts these into perspective. They found that the presence of children aged 6 or less is a strong predictor of fatigue in women, especially if they have work outside the home. However, in their study, the indicator for fatigue was a one item question on a list checking for acute complaints. Their population consisted of the people who participated in the home interview of the Dutch National Survey already mentioned in the methods section of this 
article. Our findings on the duration of the fatigue complaints show that the tiredness of those mothers with young children does not immediately make them candidates for the PF group. Together, these findings raise more questions about the processes related to the perception and reporting of fatigue, and the means employed to cope with it.

\section{Well-Being}

Our data show that fatigue, especially if it is persistent, affects daily life in terms of health experience, activities and mood. It thus confirms the importance of fatigue as a factor which influences the quality of life, and, it also confirms the association between fatigue and psychological and psycho-social vulnerability.

The data relating to deficiencies in psychological well-being for all the PFs and for the separate men and women groups of PFs are in agreement with former studies of fatigue. In general, they underline the validity of Pawlikowska et al.'s conclusion that the concordance between fatigue and psychological morbidity is inevitable-given the similarities of the criteria and measures used to define them. They also reiterate Watson and Pennebakers' conclusion (1991) that negative affectivity as a mood disposition is associated with symptom magnification.

The significant differences in psycho-social problems concern the areas of ageing, self-image and general worry. No significant dissimilarities occur in problems arising from jobs, marriage, abuse of alcohol, medicine or illegal drugs, societal change or leisure time. Some sex-specific accents can be perceived. Within the sample of men, the PFs indicate the more public and materially oriented problems of housing and life situation, while within the sample of women, the PFs reported more sexual problems, that is to say, problems in the relational and personal area. At the moment, no studies are available for the comparison of these data.

\section{A Gender Perspective}

Historically, health differences between the sexes have been attributed variously to genetic, hormonal, somatic, emotional, behavioral, cognitive, social and cultural factors. To make a distinction between the biological factors on the one side and the psychological, social and cultural factors on the other hand, the non-biological realm is frequently labelled as gender. As these distinctive realms are thought to influence each other, gender is a multi-dimensional construct that can be studied neither as a single nor as an independent variable. Therefore, it is better to speak of a gender per- 
spective from which the psychological, social and cultural dimensions are systematically analyzed for (coherence in) sex differences (Adesso, Reddy \& Fleming, 1994).

From a physical point of view the difference between the sexes in morbidity of incidental and persistent fatigue is unmistakable. But this reversal cannot be explained by a higher percentage of acute or chronic disorders among the men.

From a psychological point of view some interesting patterns in the differences and similarities between the sexes have emerged. On the one hand, considerable stress and feelings of helplessness along with a higher number of health-related actions are shown by the PFs of both sexes (though with some divergence in seeking professional help). On the other hand, PFs differ from IFs less frequently on the GHQ in the sample of men than in the sample of women. In the realm of psycho-social problems (BIOPRO) no such quantitative contrast emerges, but a partially qualitative contrast does: the PF men's profile is more public oriented and the PF women's profile more relation or person oriented. Here, one thinks of gender differences in terms of patterns of attribution and reporting problems (Watson \& Pennebaker, 1991; Leventhal, 1994). In addition, one wonders what 'other problems' the PF women could not voice in this list, as they ticked this entry significantly more often than the IF women did.

From a socio-demographic point of view the differences between the sexes appear minimal. Living alone seems to be the only factor among the social differences between PFs and IFs that differentiates the groups of men from the groups of women. But according to the absolute percentages found in the groups of PF men and women, the differences between PFs and IFs indicate a correspondence between male and female PFs. The same configuration is visible for the non-employment factor: in the PF group more men and fewer women are non-employed compared with the IFs.

As it is easy to overlook the possibility that the same socio-demographic categories may camouflage different realities for women and men, we analyzed the possible sex differences within the group of persistently fatigued. No significant differences in age and education could be identified.

\section{CONCLUSION}

The socio-demographic, psychological and psycho-social profile of the people with persistent fatigue ailments looks remarkably different from those having only incidental complaints. Significant differences between 
PFs and IFs appear to exist in sex, age, education, non-employment, and psychiatric and psycho-social problems. Being male, middle-aged, lower educated, unemployed, and having high GHQ- and BIOPRO scores is associated with an increased likelihood of persistent fatigue. But neither physical disorders-acute or chronic-nor marital status or occupational classification make a difference.

The PF and IF differences in psychological and social characteristics vary between the sexes. Between the groups of men, living alone is a discriminating factor, alongside psycho-social problems with housing and life situation. Between the groups of women the psychological and sexual problems make the difference.

The men and women in the group of PFs exhibit fewer differences than the men and women in the group of IFs. Their rates of employment and living alone are roughly comparable because the PF group includes more unemployed men and fewer homekeeping women, along with more men living alone and similar percentages of women living alone. This reduction in differences may be the outcome of as yet undefined, perhaps selective, processes.

The results of this study suggest the need for a more systematic inquiry into gender-specific differences in the development and course of fatigue complaints, and especially the path towards persistent complaints. At the very least, the gender-specific analysis has revealed the importance of living alone as a factor in the course of persistent fatigue.

In general, one should be alert to the extent that different aetiologies and mechanisms may apply within different social categories. This is especially important for the design of prospective fatigue studies. Moreover, the cross-sectional analyses of this study should be followed up with time-analyses in order to acknowledge the dynamics and multidimensionality of the processes involved.

\section{REFERENCES}

Adesso, V.J., Reddy D.M. \& Fleming R. (1994). Psychological perspectives on women's health: An introduction and overview. In Psychological Perspectives on Women 's Health. Washington: Taylor \& Francis.

Bensing, J.M. and Schreurs, K. (1995). Sekseverschillen in moeheid. Huisarts \& Welenschap, 38(9), 412-421.

Chen, M.K. (1986). The epidemiology of self-perceived fatigue among adults. Preventive Medicine, 15, 74-81, 1986.

Cox, B. Blaxter, M, Buckle A. et al. (1987). The Health and Lifestyle Survey. London: Health Promotion Trust. 
David, A., Pelosi, A., Mc Donald, E., Stephens, D., Ledger, D., Rathbone, R. and Mann, A. (1990). Tired, weak, or in need of rest: Fatigue among general practice-attenders. British Medical Journal, 301, 1191-1202, 1990.

Foets, M. \& Sixma, H. (1991). Een nationale studie van ziekte en verrichtingen in de huisartspraktijk. Basisrapport gezondheid en gezondheidsgedrag in de praktijkpopulatie. Utrecht: Nivel, 1991.

Foets, M. \& van der Velden, J. (1990). Nationale studie naar ziekten en verrichtingen in de huisartspraktijk. Basisrapport: Meetinstrumenten en procedures. Utrecht, Nivel.

Goldberg, D.P. (1972). The detection of psychiatric illness by questionnaire. London: Oxford University Press.

Kirk, John, Douglass, R., Nelson, E, Jaffe, J. Lopez, A., Ohier, J. Blanchard, C. Chapman, R., McHugo, G. and Stone, K. (1986). Chief complaint of fatigue: A prospective study. The Journal of Family Practice, 36(1), 22-30.

Kooiker, S.E. (1995). Exploring the iceberg of morbidity: A comparison of different survey methods for assessing the occurrence of everyday illness. Social Science and Medicine, 4l(3), pp 317-332.

Lamberts, H. \& Wood, M. (Eds) (1987). International Classification of Primary Care. University Press, Oxford.

Lawrie, S. M. and Pelosi, A.J. (1993). Sex differences exaggerated. British Medical Journal, 307, 564.

Lawrie, S.M. and Pelosi, A.J. (1995). Chronic Fatigue Syndrome in the community. Prevalence and associations. British Journal of Psychiatry, 166, 793-797.

Leventhal, E.A. (1994). Gender, Health and Ageing. In Psychological Perspectives on Women's Health. Adesso, V.J., Reddy D.M. \& Fleming R. (Eds). Washington: Taylor \& Francis.

Lewis, G. and Wessely, S. (1992). The epidemiology of fatigue: More questions than answers. Journal of Epidemiology and Community Heallh, 46, 92-97.

Morrison, J. (1980). Fatigue as a presenting complaint in family practice. The Journal of Family Practice, 10, 795-801.

Pawlikowska, T., Chaider, T., Hirsch, SR, Wallace, P., Wright, D.J.M., Wessely, S.C. (1994). Population based study of fatigue and psychological distress. British Medical Journal, 308, 763-766.

Ridsdale, L., Evans, A., Jerrett, W., Mandalia, S., Osler, K. and Vora, H. (1993). Patients with fatigue in general practice: A prospective study. British Medical Journal, 307, 102-106.

Sugarman, J.R. and Berg, A.O. (1984). Evaluation of fatigue in a family practice. The Journal of Family Practice, 19(5), 643-647.

Tibblin, G., Bengtsson, C, Furunes, B. \& Lapidus, L. (1990). Symptoms by age and sex. The population studies of men and women in Gothenburg, Sweden. Scandinavian Journal of Primary Health Care, 8, 9-17.

Umberson, D. (1992). Gender, marital status and the social control of health behavior. Social Science and Medicine, 34, 907-17.

Valdini, A., Steinhardt, S., Jaffe A. (1987). Demographic correlates of fatigue in a university family health center. The Joumal of Family Practice, 25(4), 103-7. 
Valdini, A., Steinhardt, S., Valiventi, J. and Jaffe, A. (1988). A one-year follow-up of fatigued patients. The Journal of Family Practice, 26(1), 33-38.

Vermande, M. \& Bijl, R. (1995). Psychische problematiek in Nederland. Utrecht: NcGv.

Watson, D. \& Penncbaker, J.W. (1991). Situational, dispositional, and genetic bases of symptom reporting. In Skelton, J.A. \& R.T. Croyle (Eds). Mental Representation in Health and Illness. New York, etc.: Springer Verlag, 60-84.

\section{HAWORTH JOURNALS ARE AVAILABLE ON MICROFORM}

All Haworth journals are available in elther microfiche or microfilm from The Haworth Press, Inc.

Microflche and microfilms are available to hardcopy subscribers at the lower "indlvidual" subscription rate. Other microform subscribers may purchase microfiche or microform at the "library" subscription rate.

Microfilm specificatlons: $35 \mathrm{~mm}$; diazo or silver.

Microfiche specifications: $105 \mathrm{~mm}$ x 184mm (4" $\times 6^{\circ}$ ); reduction ratio: $24 X$; nonsilver (diazo) positive polarity.

Microform are mailed upon completion of each volume.

For further information, contact Janette Hall, Microform Contact, The Haworth Press, Inc., 10 Allce Street, Binghamton. NY 13904-1580;

Tel: (800) 342-9678 (ext. 328); Fox: (607) 722-1424;

E-Mail: getinfo@haworth.com

Orders for microform may also be placed with University Microfilms International, 300 North Zeeb Road. Ann Arbor, MI 48106;

Tel: (303) 761-4700. 